\title{
Gerencialismo e formação de professores nas agendas das Organizações Multilaterais
}

\author{
Eneida Oto Shiroma ${ }^{1}$
}

\section{RESUMO}

A introdução da lógica gerencial nas políticas públicas há décadas apresenta desdobramentos na atual conjuntura atingindo as políticas docentes. Realizamos uma pesquisa bibliográfica e documental analisando as críticas ao gerencialismo na educação desenvolvidas na década de 1990, suas transformações na virada do milênio e problematizamos as medidas anunciadas nas agendas de Organizações Multilaterais para as próximas décadas. Neste artigo abordamos as recomendações do Banco Mundial e da Unesco para as reformas educativas em que se destacam as investidas do setor privado na educação, estratégias de redução de gastos com professores e sua desintelectualização.

Palavras-chave: Formação de professores. Política educacional. Gerencialismo.

\section{Managerialism and teacher training in Multilateral Organizations agendas}

\begin{abstract}
The introduction of managerial rationality in public policies decades ago shows its consequences in current days affecting the teaching policies. We develop a bibliographic research and documental analysis aiming at search the main criticisms to managerialism in education developed in the 90s and its transformations in the millennium turn. We search the International Organizations agendas in order to discuss their recommendations for changing education in the next decade. This article focuses upon the World Bank and Unesco proposals for education policies which stress the private sector engagement in education, cost reduction with teachers and its de-intellectualization.
\end{abstract}

Keywords: Teacher training. Education policy. Managerialism.

\section{INTRODUÇÃO}

\footnotetext{
${ }^{1}$ Doutora em Educação pela UNICAMP. Professora do Departamento de Estudos Especializados em Educação do CED/UFSC.
} 
Em 2012, o Banco Mundial (BM) publicou o livro Achieving World-Class Education in Brazil: the next agenda (BRUNS; EVANS; LUQUE, 2012) expondo claramente seu interesse em monitorar o desempenho do sistema de ensino dos paises devido a três funções primordiais que, segundo o Banco, lhe competem:

i) desenvolver as habilidades da força de trabalho para o crescimento económico sustentado; ii) contribuir para a redução da pobreza e desigualdade, fornecendo oportunidades educacionais para todos, e iii) transformar os gastos com educação em resultados educacionais - acima de tudo, aprendizagem do aluno.(BM, 2012, p.4)

Para realizá-las, o Banco propôs uma agenda para a educação brasileira em que destaca a necessidade de se "elevar a qualidade de professores" (BM, 2012, p. 8).

A preocupação de agências de planejamento econômico como o BM e a Organização para a Cooperação e Desenvolvimento Econômico (OCDE) com a educação mundial visam garantir a reprodução das condições gerais de produção (BERNARDO, 1985) necessárias à mobilidade das empresas pelos continentes em busca de vantagens competitivas que favoreçam a acumulação e o processo de valorização. Ao empenhar-se no desenho de políticas mundializadas de educação, o BM atende à necessidade do capital internacional de ter a disposição, em diversas partes do globo, trabalhadores munidos das competências que necessita para sua reprodução ampliada. As estratégias dessas agências para influenciar os rumos da economia e da educação nos países chegam ao nível do detalhamento das políticas para os docentes. Esta preocupação é evidente em publicações da OCDE tais como: "Professores são importantes: Atraindo, desenvolvendo e retendo professores eficazes" (OCDE, 2008); Evaluating and Rewarding the Quality of Teachers International Practices (OCDE, 2009) e Preparing Teachers and Developing School Leaders for the 21st Century: Lessons from around the World (SCHLEICHER, 2012).

Na região da América Latina e Caribe, também se verifica preocupação semelhante. A Unesco, no âmbito do programa Education for All (EFA) contratou o Centro de Estudios de Políticas y Prácticas de La Educación (CEPPE), da Pontifícia Universidad Católica de Chile (UC) para desenvolver um Projeto Estratégico Regional sobre políticas docentes. Fruto deste projeto veio a público, em 2011, o documento "Critérios e orientações para a elaboração de políticas docentes na região da América Latina e Caribe” (CEPPE, 2011). Em 2014 o BM publicou Professores Excelentes: Como melhorar a aprendizagem dos estudantes na América Latina e no Caribe" buscando fortalecer consensos na região em torno do professor que 
deveraim formar e dotar o Estado da autoridade necessária para o "gerenciamento de políticas da reforma do magistério" (BRUNS, LUQUE, 2014, p.47).

O interesse em influenciar a formulação das políticas para a formação docente pode ser entendido como uma manifestação fenomênica deste processo cujas determinações econômicas ficam ocultas aos educadores, gestores e grande público. Os experts dessas agências multilaterais divulgam que, para se alcançar as metas da Educação para Todos, os países precisam monitorar os resultados de aprendizagem dos alunos e investir na aferição da qualidade do professor.

Nosso objetivo, neste artigo, é analisar as agendas do BM e da Unesco visando apreender as recomendações para as reformas educativas da próxima década, estabelecendo articulações com o gerencialismo, as investidas do setor privado na educação, bem como suas repercussões sobre as políticas docentes. Para tanto, desenvolvemos uma pesquisa bibliográfica e documental sobre as agendas de Organismos Multilaterais para a educação das próximas décadas. Fundamentados no materialismo histórico dialético, buscamos compreender as reformas contemporâneas em suas articulações com as medidas decorrentes da implantação da lógica gerencial na educação.

\section{GERENCIALISMO NA EDUCAÇÃO}

A perspectiva gerencial foi introduzida nas escolas há décadas e ganha espaço na atual conjuntura. Para abordar o tema, resgatamos elementos discutidos nos anos de 1990, articulando-os aos anunciados nas agendas de Organizações Multilaterais (OM) para a próxima década - que, por delinearem o futuro, estão interferindo na formulação das políticas públicas no tempo presente. Destacamos algumas propostas de documentos do Banco Mundial e da Unesco para problematizar as tendências das políticas que anunciam.

\section{A nova gestão pública}

O enfoque gerencial na administração pública foi introduzido com vigor na GrãBretanha no governo conservador de Margareth Thatcher, iniciado em 1979. Os governos neoliberais procuraram justificar a necessidade de uma "nova gestão pública" como forma de tornar o serviço público mais ágil, eficiente e orientado para o cidadão. Este discurso foi amplamente difundido para justificar as privatizações, o encolhimento do espaço público e 
patrocinar a investida do privado nos setores não-exclusivos do Estado, como a educação e saúde pública.

Essa guinada no papel do Estado foi explicada pelos pesquisadores associada à crise do capital dos anos 1970, à mundialização do capital e ao Consenso de Washington, referências basilares para compreensão do neoliberalismo como prática de política econômica (PAULANI, 2006, p. 72). A redução de verbas públicas para as áreas sociais apresentada como uma condicionalidade imposta pelo Banco Mundial e Fundo Monitário Internacional aos países devedores indicava a necessidade de discutirmos as reformas educativas articuladas às transformações do capitalismo.

Pesquisas sobre a reestruturação produtiva no final do século $\mathrm{XX}$ revelaram que o discurso da qualidade e excelência na produção se prestou a mascarar os efeitos das estratégias de redução de custos que ampliavam a exploração por meio da competitividade espúria. A crença na modernização tecnológica e a promessa de elevar a competitividade empresarial popularizaram o "modelo japonês de administração de empresas", a Gerência da Qualidade Total, a produção enxuta, flexível, entre outras “fórmulas" que, rapidamente, foram utilizadas na gestão pública, impulsionadas pela Reforma do Estado.

Em meados da década de 1990, Bresser-Pereira à frente do Ministério da Administração Federal e Reforma do Estado anunciou a necessidade superar a administração burocrática adotando-se o modelo gerencial para fazer frente à morosidade do Estado inchado, paquidérmico dentre outras adjetivações pejorativas que visavam atacar não apenas o Estado, mas a noção de público. A Reforma do Aparelho de Estado teve como um dos objetivos "limitar a ação do Estado àquelas funções que lhe são próprias, reservando, em princípio, os serviços não-exclusivos para a propriedade pública não-estatal, e a produção de bens e serviços para o mercado para a iniciativa privada" (BRASIL, 1995, p.45).

O gerencialismo difundiu-se como um "canto de sereia" associado à ideia de um Estado enxuto, eficiente, ágil, modernizado, desburocratizado entre outras qualidades. No campo das políticas sociais, a introdução de novos marcos regulatórios combinou a descentralização com mecanismos de controle centralizado, inaugurando um novo modelo de gestão baseado na utilização eficaz dos recursos, do "fazer mais com menos" (CAMPOS, 2005). Particularmente, na área da educação, os neoliberais semearam um diagnóstico de que os problemas educacionais resultavam da "ineficácia" da gestão. Argumentavam que não faltavam recursos para a área, apenas eram mal geridos; faltava, portanto, profissionais 
eficazes dotados de competências para gerenciá-los. Deflagrou-se um período de profissionalização de gestores e professores.

Esse movimento colocou os diretores de escola no centro das agendas, responsabilizando-os pelo desenvolvimento de escolas eficazes.

\section{Avaliações e "insumos" para escolas eficazes}

De acordo como Santos (2012), o movimento das escolas eficazes se desenvolveu nos anos 1960, impulsionado pela pesquisa de Coleman, que procurava responder se a escola fazia a diferença para o aprendizado dos alunos e, se fizesse, o que a tornava diferente daquelas que não proporcionam o mesmo aprendizado. Coleman (2008) concluiu que a diferença para o aprendizado dos alunos estava menos na escola e mais no background dos alunos, ou seja, importava mais para os objetivos de aprendizado conhecer as origens socioeconômica e cultural dos alunos do que propriamente saber a qual escola pertenciam (SANTOS, 2012, p.67).

Coleman, considerado precursor dos estudos sobre eficácia escolar, "foi incisivo ao afirmar que o fator escola só poderia ser considerado importante se observada a lógica de insumos e resultados do aprendizado. Tomava as escolas como uma espécie de sistema fechado, uma caixa preta, e enfatizava que se deveria atentar para a formação de professores, livros didáticos, elaboração de currículos, pois, se fossem adequados, produziriam bons resultados" (SANTOS, 2012, p.68).

$\mathrm{Na}$ época, muitos acreditavam que eram os inputs ou insumos escolares, em termos dos equipamentos e outras condições de funcionamento da escola, que determinavam seus outputs ou resultados, segundo um modelo de entrada-saída que tratava a escola como caixa-preta e igualava o conceito de qualidade da escola ao da qualidade ou quantidade dos seus insumos (BROOKE; SOARES, 2008, p. 15).

Essa crença dos anos de 1960 reaparece revigorada na atualidade, nas recomendações dos OM recomendando uso de tecnologias de informação e comunicação, bases curriculares e avaliações externas como insumos fundamentais para produzir escolas eficazes. Eficiência, informatização e qualidade tornaram-se vedetes do discurso da modernização educacional e aos poucos, os diretores foram identificados como gerentes. 


\section{Críticas à perspectiva gerencial nos anos de 1990}

Retomando os estudos sobre o gerencialismo da primeira fase, vemos que as pesquisas sobre a perspectiva gerencial focalizaram as relações entre reestruturação produtiva, neoliberalismo e educação (GENTILI; SILVA, 1994). Discutiu-se o caráter ideológico da noção de qualidade total, e os problemas que as experiências internacionais sinalizavam como vouchers, escola charter como quase-mercado disputando alunos (DALE,1994). Pesquisadores teceram críticas severas à mercantilização do ensino e ameaça de privatizações da escola pública. Debateu-se os interesses dos empresários sobre a escola, a relação linear estabelecida entre educação e competitividade empresarial. Criticou-se a importação de conceitos de gestão do setor privado para a escola pública, bem como a transferência de recursos públicos para o setor privado.

Em suma, nos anos de 1990, as críticas sobre a introdução do gerencialismo na escola incidiram sobre a forma de pensar a escola como empresa, a educação como mercadoria e o aluno como cliente. Hoje, com olhar retrospectivo, podemos observar a grande contribuição daqueles estudos que, não se deixaram levar pelo canto da sereia, e elaboraram as primeiras problematizações e criticas à introdução do gerencialismo na educação brasileira. Fizeram a discussão das políticas evocando a necessidade de conhecermos suas determinações, situandoas em relação às transformações do capitalismo, evidenciando as relações entre capital, trabalho, política e educação. Se por um lado, naquela conjuntura, encorpavam-se as resistências ao gerencialismo, por outro, crescia também a crítica dos reformadores empresariais à ineficácia da gestão da escola pública. Articulados em Institutos e Fundações empresariais, apresentavam as taxas de repetência, evasão e baixo desempenho dos alunos como desperdícios de recursos e indicadores da má qualidade da escola pública. As avaliações externas tiveram um papel propulsor na degradação da imagem das instituições públicas educacionais veiculando sua precariedade jornais e revistas semanais de grande circulação nacional.

\section{A perspectiva gerencial adentra a escola e atinge os docentes}

Os testes em larga escala foram aplicados a alunos de todos os níveis; mas o alvo não eram os estudantes, eram os professores. Os fracos resultados nos testes serviram de justificativa para recomendar a profissionalização dos docentes, monitoramento e estabelecimento de padrões [standards]. Para Popkewitz (1997), o par "gerencialismo e 
profissionalização" foi utilizado para introduzir sistemas de racionalização no ensino visando a padronização da prática docente e sua burocratização, ocasionando perda da autonomia dos professores. Mas por que tanta preocupação com os professores?

Professores formam uma das categorias mais numerosas do serviço público, portanto a folha de pagamento da educação, juntamente com a da saúde, representa fatia significativa do orçamento público. Ademais, os professores são, também, uma das mais organizadas categorias que, quando resistem, constituem obstáculos às reformas (EVANGELISTA; SHIROMA, 2007). Dados recentes do Banco Mundial informam que "mais de sete milhões de professores entram diariamente em salas de aula na América Latina e no Caribe. Esses homens e mulheres representam 4\% da força de trabalho global da região e mais de $20 \%$ dos trabalhadores de nível técnico e superior” (BURNS; LUQUE, 2014, p.1)

Visando gerenciar este enorme contingente, o Estado lança vários programas de formação inicial, continuada, atualização, certificação etc. A perspectiva gerencial procura transformar o professor em líder. Segundo Bottery (2000, p.76), "líderes são programados para serem práticos e não contemplativos”. A perspectiva gerencialista visa desenhar um líder que saiba como fazer as coisas mais do que pensar de forma mais ampla nas razões pelas quais aquela execução está sendo requisitada.

\section{Novas críticas ao gerencialismo na virada do milênio}

Pesquisas realizadas nos Estados Unidos, Chile e Inglaterra concluíram que após tantas avaliações de larga escala e programas muito caros, não houve melhora significativa na qualidade da educação. Contudo, a reforma foi eficaz em outros aspectos: introduziu a cultura gerencial na escola alternado seu planejamento, a forma de pensar e agir dos professores, atingiu a organização escolar, o currículo, acarretando a precarização e intensificação do trabalho docente. Gasta-se em avaliação, no aprimoramento das atividades meios (tecnologias, softwares) o que poderia ser investido na formação de professores, infraestrutura da escola, apoio pedagógico e melhoria das condições de trabalho essenciais para a atividade fim.

Essa retrospectiva possibilitou perceber que ocorreu uma inflexão nas críticas ao gerencialismo nos anos 2000. Parece ter havido uma internalização no duplo sentido: 1) a introjeção e assimilação dos conceitos, práticas, valores, da cultura gerencial naturalizados em algumas instituições educacionais e 2) análises voltaram-se mais aos processos que ocorrem no interior da escola ou, no limite, no sistema educacional. Isso é preocupante. De um lado 
essas políticas forçaram os professores a mostrar resultados e responderem pelo que ocorre intramuros da escola; de outro, os pesquisadores foram chamados a explicar os problemas da escola, participar dos programas de formação em massa, colaborar para melhorar sua qualidade ou avaliá-la. Esses fenômenos ocorreram numa conjuntura expansão do Neoliberalismo de Terceira Via (NEVES, 2010), e de "recuo da teoria" (MORAES, 2001) que afetou as formas de pensar a função da escola na sociedade em que vivemos. Paradoxalmente, quanto mais as organizações econômicas - como OCDE, Fórum Econômico Mundial, Banco Mundial - planejam intervenções orquestradas na educação, e em especial nas políticas docentes, menos espaço os currículos e cursos de formação de professores dedicaram a pensar essas articulações entre educação, economia política e trabalho no capitalismo.

\section{Impactos do gerencialismo na formação docente}

Em poucos anos, essas noções que, no início, causaram estranhamento, foram assimiladas. A vedete, agora, é a avaliação, mas o alvo continua sendo os professores. A publicação de resultados nos testes e o debate sobre os indicadores alimentam o discurso sobre as falhas. Dentre as possíveis soluções, pensa-se nas que produzirão os resultados esperados pelos avaliadores. Empresas de consultorias se proliferam vendendo receitas e expertise, numa lógica simples de que se salvaram empresas da crise, salvarão as escolas. Atentemos para duas armadilhas das quais temos que nos desvencilhar: de nos vermos pelo espelho do perito (CARVALHO, 2009) e de não nos deixarmos seduzir pelo canto da sereia (MONTAÑO, 2014).

O que nos ajuda a resistir são as pesquisas que trazem à luz novas dimensões para explicar as investidas do setor privado na educação pública. São estudos que permitem compreender os determinantes externos dessas mudanças que atingem a escola, evidenciando essas relações com as transformações do capitalismo, estudos sobre as novas formas de privatização, ações das organizações sociais, financeirização da educação, parcerias públicoprivadas etc. Essas mudanças indicam que avançamos na compreensão da lógica gerencialista e por outro lado revelam as transformações do próprio gerencialismo, evidenciando sua dinâmica, avanços no campo educacional.

No tempo presente, as investidas do grande capital aparecem sem subterfúgios nas agendas internacionais. Em 2005, o Banco Mundial publicou a atualização de sua estratégia para a educação destacando duas prioridades: a necessidade de maximizar o impacto da 
educação para o alivio da pobreza e incutir a orientação para resultados. As demandas passaram a ser mais diretas em decorrência da parceria estabelecida pelo Fórum Econômico Mundial com a Unesco.

O propósito do Fórum Econômico Mundial é "assegurar que os interesses corporativos avancem sobre outros e minem os processos democráticos de se decidir prioridades e políticas de governo" (BEDER, 2006). Pouco tempo depois, em 2009, a Unesco publicou três volumes de "Padrões de Competência em TIC para professores" explicitando as metas para a formação docente e as competências esperadas do professor. Para a ampla maioria dos alunos, propõe-se a "Alfabetização em abordagem de alfabetização em tecnologia". A meta política deste programa é "preparar uma força de trabalho capaz de adotar novas tecnologias para apoiar a produtividade econômica". Para um grupo menor, a Unesco propõe a "Abordagem de aprofundamento do conhecimento" cuja meta política é "aumentar a habilidade da força de trabalho para agregar valor ao resultado econômico aplicando o conhecimento das disciplinas escolares para solucionar problemas complexos que são encontrados em situações de trabalho e de vida no mundo real". A terceira frente, para um grupo restrito, é a da "Abordagem de Criação do Conhecimento", tendo em vista atingir a meta política de "aumentar a produtividade criando uma força de trabalho permanentemente envolvida com a criação de conhecimento e inovação, beneficiando-se dela" (UNESCO, 2009, p.10).

As publicações destas metas expressam a perspectiva da Unesco para o ensino de Tecnologias de Informação e Comunicação (TIC), e na formação do professor encarregado de ensiná-las às próximas gerações. No detalhamento dos objetivos que definem um perfil de docente, lê-se que o professor deverá ser capaz de: "I.D.6. Usar uma ferramenta de busca para fazer uma pesquisa boleana por palavra-chave; I.D.7. Criar uma conta de e-mail e usá-la para uma série contínua de troca de mensagens" (UNESCO, 2009, p.10).

Ficam evidentes as contradições dessa política supostamente voltada ao incentivo do conhecimento, da inovação e da qualidade ao lado de medidas propulsoras da precarização e da desintelectualização do professor. Evidencia-se o caráter instrumental da educação proposta pelo capital por meio dos OM e a natureza interesseira do "direito à aprendizagem".

\section{Holofotes na aprendizagem, ensino na penumbra}

O BM anuncia vários objetivos para aliviar a pobreza e afirma que a educação é um "instrumento poderoso" para reduzir a desigualdade e promover a prosperidade 
compartilhada. Seus consultores alegam que a Aprendizagem para Todos' (2011) garantirá a todas as crianças e jovens o direito de ir à escola e adquirir o conhecimento e as habilidades de que necessitam para terem vidas saudáveis, produtivas e também obterem um emprego. Os documentos do BM propagam a ideia de que o "motor" que impulsiona esse movimento são as pessoas que aprendem, dentro e fora da escola, desde a Educação Infantil até ao mercado de trabalho. Essa proposta está prevista para se efetivar nesta década (2011-2020) por meio de reformas nos sistemas de educação dos países.

O BM explicita seus propósitos ao propor a criação de uma "base global de conhecimentos fortes' para liderar essas reformas, e indica que mesmo em ambientes de "aprendizagem fraca", a maioria dos estudantes consegue adquirir competências na escola. Assim, por meio de investimento em avaliações de sistemas de aferição de impactos e verificação da aprendizagem e de competências, o Banco sinaliza reformas necessárias para melhorar os resultados de aprendizagem, ressaltando que a prestação dos serviços educacionais pode ser realizada pelo setor privado. (BM, 2011 p.6).

Enfatizam que novos instrumentos de avaliação podem fornecer mais informações detalhadas sobre as capacidades dos países em um grande conjunto de áreas da política da educação desde o desenvolvimento na primeira infância, avaliação dos estudantes e política de professores, à equidade e inclusão, educação terciária e desenvolvimento de competências. $\mathrm{O}$ BM recomenda aos gestores do sistema educacional divulgarem os indicadores educacionais, pois essa informação vital permitirá aos decisores políticos e às organizações da sociedade civil tomarem decisões mais bem informadas sobre reformas e intervenções necessárias na educação atuando sobre as falhas na "cadeia de resultados".

Associam os níveis elevados de desemprego entre os jovens à incapacidade de os sistemas de educação formarem jovens com as "competências corretas" para o mercado de trabalho e incentivam que a aprendizagem seja encorajada desde cedo e continuamente, tanto dentro quanto fora do sistema escolar.

A agenda do BM destaca a necessidade adoção de políticas de accountability de modo a responsabilizar as escolas e os professores em responsáveis pelos trabalho com o ensino esperado; tornar públicas as diferenças no nível de desempenho; formas de análise das informações educacionais, a fim de avaliar o desempenho das escolas para que assim possam ser aplicadas recompensas ou sanções em função dos resultados alcançados.

Anunciando um sistema de melhoramentos na educação, no documento Teacher Policies around the world (BM, 2010), o BM propõe oito objetivos: estabelecer expectativas 
claras para os professores; atrair os melhores profissionais para o ensino; preparar os professores com "formação útil" e experiência; relacionar as habilidades dos docentes com as necessidades dos estudantes; monitorar o ensino e a aprendizagem; apoiar os docentes para melhorar sua instrução; motivar os docentes para o desempenho; avançar para uma maior descentralização e autonomia das escolas, e fornecimento de informações para diversos atores.

As recomendações do $\mathrm{BM}$ incluem reforçar os sistemas educacionais de modo a alinhar a sua governança à gestão de escolas e professores, às regras de financiamento e mecanismos de incentivo, com o objetivo da aprendizagem para todos, significa também estabelecer um ciclo claro de retorno entre o financiamento e os resultados. Alegam que porque 'as falhas de governação e responsabilização têm geralmente os seus efeitos mais nefastos nas escolas que servem os grupos mais desfavorecidos, este sistema de gestão promove equidade educacional para além da eficiência'" (BM, 2011, p. 6). Para tanto, o Grupo Banco Mundial e a Internacional Finance Corporation propõem-se a trabalhar em conjunto para aumentar o conhecimento sobre o papel do setor privado na educação e ajudar os países a criar ambientes de política e estruturas normativas que alinhem os esforços do setor privado por meio de parcerias estratégicas em nível nacional e internacional, a fim de melhorar os sistemas educacionais.

Os consultores do BM concentrar-se-ão em ajudar os países parceiros a consolidar a capacidade nacional para reger e gerir sistemas educacionais, implementar padrões de qualidade e equidade, medir o sistema de desempenho com relação aos objetivos nacionais para a educação e apoiar a definição de políticas e inovação com base comprovada. Reforçar os sistemas de avaliação com a ajuda de ferramentas de comparação, juntamente com dados de informação, para avaliar a capacidade de um sistema educacional para melhorar os resultados de aprendizagem; avaliações da aprendizagem e realização de objetivos que abranjam as competências básicas de leitura e aritmética, bem como outras aptidões, incluindo pensamento crítico, solução de problemas e aptidões para trabalhar em equipe; e avaliações de impacto e outro trabalho analítico que possam informar políticas e intervenções, juntamente com o intercâmbio de conhecimentos.

No que tange às políticas docentes, as agendas do BM propõem: melhoria da qualidade dos professores e, para o Brasil especificamente, recomenda o recrutamento de indivíduos da mais alta capacidade, apoio contínuo à prática e atribuição de recompensa pelo desempenho. O professor é tido como elemento central para o sucesso escolar dos alunos. A 
qualidade da educação resultaria, na visão dos consultores do $\mathrm{BM}$, de práticas dos professores, o insucesso da aprendizagem se daria por "professores ruins" ou "práticas incompetentes" (DELANNOY; SEDLACEK, 2000).

Nessa perspectiva, recriminam aos cursos de formação docente por serem muito teóricos, e não repercutirem diretamente sobre os resultados dos alunos. Alegam que os programas de formação dos professores estão, em grande medida, desvinculados da prática da sala de aula, e com uma prática docente deficiente os estudantes serão "fracos". Delannoy e Sedlacek (2000) enfatizam que se a formação docente em nível superior não estiver respondendo às expectativas esperadas, ou seja, se os professores não estiverem bem preparados para ensinar, causarão danos à educação, pois o bom desempenho dessa tarefa depende da prática por ele empregada.

Em síntese, a agenda do BM expressa a preocupação de seus acionistas em administrar a pobreza, em assegurar que a população vulnerável, os mais desfavorecidos, tenham acesso à escola, adquiram competências básicas, para terem vidas saudáveis, produtivas e também obterem um emprego. Fica evidente que este é um projeto do capital para a classe trabalhadora. As marcas do discurso deixam clara a intenção do Banco, de intervir fornecendo conhecimento para a realização de reformas nos sistemas nacionais de educação, abrindo espaço para o setor privado atuar na educação pública, orientando os países a criarem ambiência para a institucionalização dessas políticas, bem como adequar suas estruturas jurídico-normativas de modo a alinhar os esforços do setor privado com a demanda social por educação por meio de parcerias estratégicas. Trata-se de introduzir uma nova forma de governar a educação, alinhando a gestão de escolas e professores, regras de financiamento e mecanismos de incentivo, de modo a estabelecer um ciclo claro de retorno entre o financiamento e os resultados. Recomendam antecipar o ingresso na escola para acelerar a aprendizagem, adiantando o desenvolvimento de aptidões requeridas pelo mercado que reorientarão a definição dos currículos.

O BM propõe que a base curricular nacional balize tanto o ensino na educação básica quanto as reformas na formação docente, recomendação que deixa evidente o viés pragmático dessa agenda.

A maioria das políticas recomendadas pelos OM e pelos Projetos Regionais de educação da América Latina, como o PRELAC, PREAL e o PERDALC destacam que a formação inicial, continuada e a carreira docente necessariamente dependem de profissionais com "formação relevante", "preparados" e "bem treinados" para proporcionarem uma 
escolarização relevante a seus estudantes. Há consenso nas agendas em torno da ideia de que a má qualidade da educação se deve às práticas "ineficazes" dos professores. Além de serem taxados de desqualificados, os consultores do BM apontam os professores como o mais caro e importante recurso do sistema educacional brasileiro (DELANNOY; SEDLACK, 2000; BRUNS; LUQUE , 2012).

Os autores alegam que o fracasso na aprendizagem dos alunos se dá pela falta de "boas" práticas, ou seja, na visão do BM, a aprendizagem 'irrelevante' deve-se aos "professores ruins" e às "práticas incompetentes". Reclamam dos cursos universitários de formação de professores alegando que a teoria não 'gera'" resultados e nem faz com que os professores "'melhorem" suas práticas. Chamamos a atenção para o fato de que essas críticas em relação aos cursos de formação de professores são reiteradas, já foram apontadas em 2000. A ênfase no praticismo é reproduzida nas novas diretrizes para os cursos de formação de professores no Brasil, Resolução $n^{\circ}$ 2, de 2015, em que se eleva a carga horária destinada à prática como componente curricular.

\section{Formação docente na berlinda ${ }^{2}$}

A Política Nacional de Formação de Professores da Educação Básica do governo Temer (PMDB), após o golpe de 2016, foi anunciada então, Secretária Executiva do MEC, Maria Helena Guimarães Castro, ex-presidente do INEP nas gestões de Fernando Henrique Cardoso (PSDB), apresenta as medidas polêmicas como a criação de uma "Base Nacional de Formação Docente" para nortear o currículo da formação de professores, sem distinguir claramente sua função em relação às "Diretrizes Curriculares Nacionais (DCN)", Resolução CNE/CP n ${ }^{\circ}$, de $1^{\circ}$ de julho de 2015 e a implantação do "Programa de Residência Pedagógica".

Uma medida primordial seria proceder à revisão da formação inicial e continuada dos professores para alinhá-las à BNCC. Isso se daria por mudanças no currículo, aumento das horas destinadas à pratica, introdução da residência pedagógica, e mais recentemente a curricularização da extensão dentre outras medidas que alteram o projeto formativo das universidades.

\footnotetext{
${ }^{2}$ Este tópico foi elaborado com base na tese de Anibal Brito Neto (2018) que analisa a política nacional de formação docente dos governos do Partido dos Trabalhadores (2003-2016) e aborda as primeiras reformas educacionais do governo Temer.
} 
A Residência Pedagógica foi anunciada como panaceia por Castro (2017), para reformar os “currículos extensos que não oferecem atividades práticas". Castro, ex-presidente do INEP nas gestões do governo FHC, resgata as proposições do governo do PSDB da década de 1990, quando também propuseram Diretrizes Curriculares para a formação de professores que deveria ocorrer exclusivamente nos, ainda por criar, Institutos Superiores de Educação.

As versões preliminares das Diretrizes Curriculares para a Formação Inicial de Professores da Educação Básica ressaltavam a importância de que o graduando experiencie “durante todo o processo de formação, as atitudes, modelos didáticos, capacidades e modos de organização que se pretende venham a ser concretizados nas suas práticas pedagógicas”. Guiomar Namo de Mello (2000), no texto "Formação inicial de professores para a educação básica: uma (re)visão radical" já sugeria a "residência escolar" como forma de remodelar a formação de professores subtraindo-lhe de teoria, enfatizando a prática como componente central da formação docente em oposição à proposta das Entidades de Educadores, que defendiam uma "formação universitária a todos os professores, com sólida base docente onde teoria e prática estivessem articuladas".

Vemos que a residência pedagógica reedita uma velha política com nova roupagem reiterando a epistemologia da prática, a pedagogia das competências, a formação pragmática, utilitarista, voltada a administrar os problemas que se manifestam na escola, revelando a concepção funcionalista que embasa esta política.

A formação de professores realizada predominantemente pelo setor privado, à distância, representa uma oferta massificada empobrecida de conteúdos indispensáveis à constituição do professor como um intelectual da educação. Essa tendência tem continuidade no campo da Formação Continuada, com a expansão dos mestrados profissionais, assim como cursos de especialização a distancia e intercâmbios internacionais que alimentam o mimetismo pedagógico. São políticas que ao anunciar a Educação como um bem público e estratégico (OREALC/UNESCO, 2005) fomentando a disputa para elevação dos indicadores educacionais nos rankings, incentivaram o engajamento do setor privado na educação, ocorreu de forma inconteste no movimento pela Base, e na Reforma do Ensino Médio.

Castro (2017) anuncia, também, a "Plataforma de Formação Continuada" que se, por um lado, remete à valorização do magistério, por outro oculta o caráter centralizador para assegurar o alinhamento à Base e a transferência de fundos públicos para organizações privadas fornecedoras das tecnologias para monitoramento e avaliação de alunos e 
professores. Segundo Brito Neto (2018, p.243), em março de 2017, a Fundação Lemann anunciou a parceria com o Google.org para o lançamento de uma Plataforma Digital, sob Liderança da Nova Escola ${ }^{3}$, em um investimento da ordem de US\$ 15,8 milhões. A proposta seria oferecer um "conjunto de recursos pedagógicos alinhados à Base Nacional Comum Curricular" a ser acessado por "aplicativo móvel gratuito projetado para funcionar mesmo onde a conectividade ainda é lenta”. Assim, o empresariado encontra nas políticas públicas para educação um nicho promissor para obtenção de ganhos econômicos e políticos: vende seus produtos e assegura a difusão dos valores, informações e metodologias para fomentar a sociabilidade requerida pelo capital no século XXI.

\section{CONSIDERAÇÕES FINAIS}

As pesquisas desse terceiro momento demostram que o interesse do capital pelas escolas públicas não se limita à mercadorização do ensino, mas abrange várias outras atividades que podem e estão sendo terceirizadas para a iniciativa privada. Mais que obter lucros imediatos com a prestação de serviços, interessa aos grandes grupos empresariais, tomar assento nas mesas que definem os rumos das políticas públicas. Este é um canal de acesso a informações privilegiadas sobre as áreas de interesse prioritário, onde o governo vai investir, os produtos e serviços que serão demandados, e a oportunidade de desfrutar das vantagens de ter o Estado como cliente (SHIROMA, 2015).

Analisar as críticas feitas à introdução do gerencialismo na escola pública em diferentes momentos, permitiu-nos observar as transformações no próprio objeto, no modo de gerir escola e de fazer política pública, as articulações entre público e privado, internacional e nacional para refletir sobre dimensões da gestão da educação no tempo presente. Descortinase uma disputa de classes pela definição das prioridades para políticas públicas. Os reformadores internacionais concorrem para o direcionamento da formação de docentes, de alunos por meio de definições de currículo. Buscam, assim, reconverter os professores (EVANGELISTA, 2008) definindo o que devem saber e podem fazer. Ao estabelecerem os standards docentes, procuram reconfigurar a escola pública, visam enfraquecer os sindicatos e desorganizar as lutas coletivas.

\footnotetext{
3 Associação criada em 2015 tendo, a Fundação Lemann como mantenedora. Sua missão é "transformar a Educação brasileira por meio de conteúdos e serviços de alta qualidade para professores e gestores do Brasil". Publica as revistas e sites Nova Escola e Gestão Escolar publicadas , por 30 anos, pela Fundação Victor Civita.
} 
Há tempos os consultores recomendam estratégias de corte de gastos e de gerenciamento de professores. Nos últimos anos, as ameaças foram claramente explicitadas. No documento Professores Excelentes, o Banco Mundial anuncia os desafios para as políticas docentes: recomendam aos governos,

\begin{abstract}
cortar os professores de baixo desempenho para dar lugar a novos contratados de mais qualidade. Com reduções em alguns casos de $20 \%$ ou mais no tamanho do corpo docente até 2025 , é fundamental gerenciar tanto as saídas dos professores como o recrutamento seletivo"; "apoiar o recrutamento de novos profissionais com padrões mais elevados". Reconhecem que o maior desafio para elevar a qualidade dos professores não é fiscal nem técnico, mas político, porque os sindicatos dos professores em todos os países da América Latina são grandes e politicamente ativos (BRUNS; LUQUE, 2014, p.34).
\end{abstract}

A orientação para a formação de consensos envolve a estratégia perversa na medida em que pretende associar, perante a opinião pública, os líderes empresariais, sociedade civil e governo, de forma bem unida, formando uma união que represente os "interessados no diálogo" com os professores organizados, escanteados num vértice oposto, supostamente o dos desinteressados, como revela o excerto

Os líderes políticos podem criar alianças pró-reformas eficazes com líderes empresariais e a sociedade civil por meio de campanhas de comunicações que expõem claramente as falhas atuais do sistema educacional e a importância da melhoria na educação para a competitividade econômica. Unir de forma bemsucedida dois lados do triângulo de interessados (sociedade civil e governo) em um diálogo com o terceiro (professores organizados) pode criar espaço político para a adoção de reformas, incluindo três delas que desafiam os interesses dos sindicatos (avaliação de desempenho individual do professor, pagamento diferenciado por desempenho e perda da estabilidade no emprego) (BRUNS; LUQUE, 2014, p. 49; grifo nosso).

Essas medidas estão sendo adotadas em redes municipais e estaduais e precisamos estar preparados, organizados. Ataques semelhantes são respondidos com resistência no Chile, onde o neoliberalismo primeiro instalou suas bases na América Latina, mas educadores e estudantes não sucumbiram, lembrando que a realidade é repleta de contradições. No Brasil, ao olharmos a escola hoje, também não vemos só seres adaptados, conformados, isolados e individualistas. Vemos, também, indignação, protestos, organização de movimentos coletivos, lutas, greves, ocupações estudantis, reações às medidas autoritárias de reorganização, militarização, terceirização da gestão para iniciativa privada, privatização, precarização, entre outros ataques. Vemos estudantes lutando por merenda, por melhores condições de estudo, junto a professores e outros trabalhadores lutando por melhores condições de trabalho, salário, carreira e formação, mostrando que não há consenso, que a ótica gerencialista não tem um 
projeto de futuro que possa contemplar a todos, é excludente, perversa e incompatível com educação.

A crítica de associações de pesquisa a implantação introdução de competências socioemocionais nos currículos, a resistência de professores e escolas as inúmeras avaliações de larga escala, os protestos contra as Organizações Sociais na educação, mostram que, apesar das medidas coercitivas, não sucumbimos, há projetos em disputa e as propostas internacionais, por mais que tenham buscado orquestrar sua intervenção na educação pública, não conseguiu produzir a harmonia pretendida. Vozes dissonantes ecoaram, mostrando o contraponto, as contradições, evidenciando que "o canto da sereia” está desafinado.

\section{REFERÊNCIAS}

BANCO MUNDIAL. Education Sector Strategy Update. Achieving education for all, broadening our perspective, maximizing our effectiveness. Washington, DC, 2006.

BANCO MUNDIAL. Learning for All. Investing in people's knowledge and skills to promote development. World Bank Group. Education Strategy 2020, Washington, 2011.

BANCO MUNDIAL. Teacher Policies around the world, 2010.

BEDER, Sharon. Suiting Themselves: How Corporations Drive the Global Agenda. London: Earthscan, 2006.

BOTERY, Mike. Education, policy and ethics. London: Continuum, 2000.

BRASIL. Presidência da República. Plano Diretor da Reforma do Aparelho de Estado. Brasília, 1995.

BRASIL.MEC. Resolução CNE/CP n 2, de $1^{\circ}$ de julho de 2015. Define as Diretrizes Curriculares Nacionais para a formação inicial em nível superior (cursos de licenciatura, cursos de formação pedagógica para graduados e cursos de segunda licenciatura) e para a formação continuada. Brasília, 2015.

BROOKE, Nigel; SOARES, José F. (org.) Pesquisa em eficácia escolar: origens e trajetória. Belo Horizonte: Editora UFMG, 2008.

BRUNS, Barbara; EVANS, David; LUQUE, Javier. Achieving world class education in Brazil: the next agenda. Washington: The World Bank, 2012.

BRUNS, Barbara; LUQUE, Javier. Professores excelentes: Como melhorar a aprendizagem dos estudantes na América Latina e no Caribe. Washington, D.C.: Banco Mundial, 2014.

CAMPOS, Roselane Fátima. Fazer mais com menos - gestão educacional na perspectiva da CEPAL e da UNESCO. GT: Estado e Política Educacional / n. 05. In: 28. Reunião Anual da ANPEd. Caxambu, MG, 16 a 19 de outubro de 2005. 
CARVALHO Luis Miguel. Governando a educação pelo espelho do perito: uma análise do PISA como instrumento de regulação, Educação e Sociedade, Campinas, v.30, n.109, 2009. p.1009-1036.

CASTRO, Maria Helena Guimarães. Política Nacional de Formação de Professores. Brasília: MEC, 2017. Disponível em:

$<$ http://portal.mec.gov.br/index.php?option=com_docman\&view=download\&alias=74041formacao-professor-final-18-10-17-pdf\&category_slug=outubro-2017-pdf\&Itemid=30192>. Acesso em: 06 fev 2018.

COLEMAN, James S. Desempenho das escolas públicas. In. BROOKE,Nigel e SOARES, José F. (org.). Pesquisa em eficácia escolar: origens e trajetória. Belo Horizonte: Editora UFMG, 2008. p. 26-32. Texto extraído do capítulo 3 do Summary Report: equality of educational opportunity, elaborado por J. S. Coleman.

DALE, Roger. O marketing do mercado educacional e a polarização da educação. In: GENTILI, Pablo; SILVA, Tomaz T. Neoliberalsimo, qualidade total e educação. Petrópolis/RJ: Vozes, 1994.

EVANGELISTA, Olinda; SHIROMA, Eneida O. Professor: protagonista e obstáculo da reforma. Educação e Pesquisa, São Paulo, v. 33, n. 3, set./dez. 2007, p. 531-541.

EVANGELISTA, O. Rede Kipus e reconversão docente. In: XIV Encontro Nacional de Didática e Prática de Ensino/ENDIPE, 2008, Porto Alegre. XIV ENDIPE. Trajetória e processos de Ensinar e Aprender: lugares, memórias e culturas. Porto Alegre: EdiPUCRS, 2008 .

GENTILI, Pablo A.; SILVA, Tomas T. (orgs.). Neoliberalismo, Qualidade Total e Educação - Visões Críticas. Petrópolis, RJ: Vozes, 1994.

LAVAL, Cristian. A Escola não é uma empresa: o neo-liberalismo em ataque ao ensino público. Londrina: Editora Planta, 2004.

LIMA, Licínio C. A escola como organização educativa: uma abordagem sociológica. 3ed. São Paulo: Cortez, 2001.

MELLO, G. N. Formação inicial de professores para a educação básica: uma (re)visão radical, São Paulo em Perspectiva, São Paulo, v. 14, n. 1, p. 98-110, Jan./Mar. 2000.

MONTAÑO, Carlos. O canto da sereia. Crítica à ideologia e aos projetos do Terceiro Setor. São Paulo, SP: Cortez, 2015.

MORAES, Maria Celia M. Recuo da teoria: dilemas na pesquisa em educação. Revista Portuguesa de Educação, Braga, vol. 14, n. 1, 2001, p. 7-25.

NETO, Aníbal Correia Brito. Política Nacional de Formação de Professores no Brasil (2003-2016) como expressão da governança global. Tese (Doutorado em Educação) Florianópolis; Universidade Federal de Santa Catarina, 2018. 
NEVES, Lúcia M.W. (Org.) A direita pelo social e a esquerda pelo capital. São Paulo: Xamã, 2010.

OREALC/UNESCO. La educación como bien público y estratégico: encuentro regional Unesco. Cartagena das Indias: Unesco/Unicef, 2005.

PAULANI, Leda M. O projeto neoliberal para a sociedade brasileira: sua dinâmica e seus impasses. In: LIMA, J.C.F. e NEVES, Lucia M.W. Fundamentos da educação escolar do Brasil contemporâneo. Rio de Janeiro: Fiocruz, 2006. p. 67-107.

POPKEWITZ, Thomas S. Reforma educacional: uma política sociológica. Porto Alegre: Artes Médicas, 1997.

SANTOS, Fabiano Antonio. O plano de desenvolvimento da escola e a produção do consentimento ativo. Tese (Doutorado em Educação). Florianópolis: Universidade Federal de Santa Catarina, 2012.

SHIROMA, Eneida Oto e EVANGELISTA, Olinda. Profissionalização como estratégia de gerenciamento de professores. Revista de Estudos Curriculares, Braga n. 1, 2003. p.267281.

SHIROMA, Eneida Oto. O Estado como cliente: interesses empresariais na coprodução da inspeção escolar. Trabalho Necessário, Niterói, v. 22, 2015, p. 57-79.

UNESCO. PADRÕES DE COMPETÊNCIA EM TIC PARA PROFESSORES. Diretrizes de implementação versão 1.0. Brasilia: Unesco, 2009. Disponível em <http://unesdoc.unesco.org/images/0015/001562/156209por.pdf>. Acesso em 18mar 2018. 